\title{
Autopsy Analysis of Suicidal Hanging Cases at Dhaka Medical College
}

\author{
Farial Naima Rahman ${ }^{1}$, Mushtaq Ahmad ${ }^{2}$, Md. Nur Hossain ${ }^{3}$, Sanjida Akhter ${ }^{4}$, Prodip Biswas 5
}

\begin{abstract}
Background: Hanging is one of the common methods of suicide in the world. The rate of suicide by hanging is increasing day by day in Bangladesh. Suicide by hanging is the act of intentionally killing oneself by suspension from an anchor point or ligature point (e.g., an over head beam or hook) by a ligature or jumping from a height with a noose around the neck. Hanging is a very simple method of suicide that does not require complicated techniques. The materials required are easily available, and a wide range of ligature can be used, so most of the people commit suicide by suspension from a height with a ligature around the neck. Objective: The objective of this study was to find out demography of hanging, its distribution according to age group, sex, common ligature materials used by victims, observed post mortem findings and in this way try to identify the causative factors and develop the preventive measures that are essential to reduce death due to hanging. Materials and method: A retrospective study was done on the basis of $3 \mathrm{rd}$ copies of postmortem reports preserved in the department of Forensic Medicine, Dhaka Medical College, Dhaka, Bangladesh for the period of 2 years, (from January 2008 to December 2009) with the permission of the autopsy surgeons. Results: Out of 574 cases, 159 (27.71\%) were male and 415 (72.29\%) female. Among them 304 $(52.96 \%)$ were married and $270(47.04 \%)$ were unmarried. Most of the victims (46.86\%) were from the age group 21-30 years. Dopatta (orna) was the commonest (41.28\%) ligature material. Conclusion: To reduce the number of suicide by hanging a well designed and comprehensive programme is needed, which will identify the causative factors and which might help in prevention of suicidal hanging.
\end{abstract}

Keywords: Hanging; autopsy; suicide.

Delta Med Col J. Jan 2016;4(1):9-12

\section{Introduction}

Hanging (self suspension) is that form of asphyxia which is caused by suspension of the body by a ligature which encircles the neck, the constricting force being the weight of the body. ${ }^{1}$
Sometimes the body completely suspends from above, which is called complete hanging, sometimes a portion of body touches the ground, which is called incomplete or partial hanging. ${ }^{2}$

1. Lecturer, Dept. of Forensic Medicine, Armed Forces Medical College, Dhaka Cantonment, Dhaka, Bangladesh.

2. Associate Professor (Classified Specialist) \& Head, Dept. of Forensic Medicine, Armed Forces Medical College, Dhaka Cantonment, Dhaka, Bangladesh.

3. Professor \& Head, Dept. of Forensic Medicine, Delta Medical College, Dhaka, Bangladesh.

4. Assistant professor, Dept. of Forensic Medicine, Delta Medical College, Dhaka, Bangladesh.

5. Lecturer, Dept. of Forensic Medicine, Dhaka Medical College, Dhaka, Bangladesh.

Correspondence: Lt Col Dr. Mushtaq Ahmad. e-mail: mushtaq863@yahoo.com 
Suicide by hanging is one of the major causes of unnatural death especially in young female in our country. Suicide is defined as a self inflicted cause of death. Suicidal death also indicates the socio-economical and health status of the community. ${ }^{3}$ Hanging produces painless death for the victims and there is no costs involvement other than that of the ligature material. A thin rope around the neck will cause unconsciousness in 15 seconds. ${ }^{4}$ So people prefer it as a common method of suicide. ${ }^{5}$ Our study focused upon the autopsy reports of suicidal death occurred by hanging, preserved in the department of Forensic Medicine at Dhaka Medical college in the years from 2008-2009.

\section{Materials and Method}

A retrospective study was done on the basis of $3 \mathrm{rd}$ copies of postmortem reports preserved in the department of Forensic Medicine, Dhaka Medical College, Dhaka, Bangladesh for the period of 2 years, (from January 2008 to December 2009) with the permission of the autopsy surgeons.

During the study period 574 cases were of suicide by hanging. Their ligature material, types of knots and suspension points were evaluated.

\section{Results}

Out of 574 reported suicidal hanging cases, 159 (27.71\%) were male and $415(72.29 \%)$ were female victims. Among them 304 (52.96\%) were married and 270 (47.04\%) were unmarried. Marital disharmony/quarrel between couples was the commonest $172(29.96 \%)$ cause of suicidal hanging (Table I). Most of the victims 269 (46.86\%) were from the age group 21-30 years (Table II). Dopatta (orna) was the commonest 237 (41.28\%) ligature material (Table III).

Table I: Suspected causes of hanging $(\mathrm{N}=\mathbf{5 7 4})$

\begin{tabular}{lcc}
\hline Suspected causes of hanging & Frequency & Percentage \\
\hline Marital disharmony/ quarrel between couples & 172 & 29.96 \\
Various family problems & 85 & 14.81 \\
Mental depression & 77 & 13.42 \\
Drug addiction & 65 & 11.32 \\
Failure in love affairs & 47 & 8.19 \\
Unwanted pregnancy & 37 & 6.44 \\
\hline
\end{tabular}

Table II: Age distribution of the victims $(\mathrm{N}=574)$

\begin{tabular}{lcc}
\hline Age (years) & Frequency & Percentage \\
\hline $01-10$ & 5 & 0.87 \\
$11-20$ & 31 & 5.40 \\
$21-30$ & 269 & 46.86 \\
$31-40$ & 251 & 43.73 \\
$41-50$ & 15 & 2.61 \\
Above 50 & 3 & 0.53 \\
\hline
\end{tabular}

Table-III: Different ligature materials used for hanging $(\mathbf{N}=574)$

\begin{tabular}{lcc}
\hline Ligature materials & Frequency & Percentage \\
\hline Orna ( dopatta) & 237 & 41.28 \\
Jute rope & 195 & 33.97 \\
Shari & 42 & 7.32 \\
Nylon rope & 28 & 4.88 \\
Lungi & 25 & 4.35 \\
Kamiz & 21 & 3.68 \\
Electric wire & 03 & 0.52 \\
\hline
\end{tabular}

\section{Discussion}

The study showed that suicidal hanging is one of the major causes of unnatural death in our country. In our study, suicidal hanging was observed in all age group, but majority cases were within 21 to 30 years age group. This is the most active period of one's life and there are great fluctuations of emotions of this group. Young people get frustrated due to various reasons such as unemployment, poverty, failure in examination, failure in love, etc. All these causes form the motivational factors to terminate their lives. Hanging is one preferred means of committing suicide in this subcontinent. However deaths by hanging may be accidental or even homicidal. The latter is very rare. ${ }^{6}$

Usually partial hanging is almost always suicidal, unless otherwise proved. There may be a suicidal note left behind. There should be a motive for committing suicide. ${ }^{7}$ We found that most of victims $(73 \%)$ were committing suicide by hanging is more prevalent among the females. This may be due to the fact that there are too many influencing or provoking factors like lack of family bonding, emotion, sentiment, poverty, dowry agreement, 2nd marriage of husband, failure in love, pregnancy resulting from rape, failure in examination, eve teasing, etc. which eventually lead to suicidal attempts. ${ }^{8}$ The 
incidence of sexual harassment and eve teasing in Bangladesh are rapidly increasing. The young or teen aged girls usually commit suicide in order to escape from sexual harassment or eve teasing. In recent years in Bangladesh the researchers have documented the prevalence of physical, sexual and emotional abuse, association between violence and physical and mental health. ${ }^{9}$ In our study, majority were unmarried. Marital disharmony was the commonest cause. In our country males are predominantly earning member of the family and husbands torture or harass the wives for various family problems including dowry. The female members have low frustration tolerance level and weak protective value in social institute like family especially in low socio economic condition. Due to repeated physical and mental torture, sometimes they go beyond the threshold level of self control and commit suicide. In case of male; poverty, lack of job, family problems, defamation, and alcoholism are the main reasons for suicidal hanging. These causative factors are similar to those in India. ${ }^{10}$ A five year study (1998-2002) in Turkey also showed that hanging is the commonest method of suicide in Istanbul. ${ }^{11} \mathrm{~A}$ study in Lithuania has shown that a total of 8324 suicides were committed during 1993-1997 and 7823 between 1993-2002. Among all these registered suicides cases, hanging was the commonest method used to commit suicide. ${ }^{12}$

In this study majority of the victims were from the age group 21-30 years. Study has shown that people belonging to this age group are also common victims of hanging in other countries. ${ }^{13}$ Majority of the victims used dopatta (orna) as ligature material to commit suicide. Around 83\% cases were the victims of complete hanging (body was fully suspended). Salwar kamiz with dopatta (orna) is the most common dress worn by the young female population of our country, hence dopatta (orna) - about ten feet long piece of cloth is used as commonly available ligature material for hanging. The victims also hang themselves from ceiling by rope, electric wire, etc. In low socio economic family young teen aged girls are the earning members like garments or other industrial workers. They commit suicide due to mental depression, drug addiction, failure in love affairs, unwanted pregnancy and these problems are common among this age group. Even failure in examination can also lead to suicide, which is a tragic and preventable public health problem all over the world. In both developed and developing countries the suicide rate among young people appear to be rising. ${ }^{14}$ Most death were due to asphyxia by using different ligature material like dopatta (orna), shari, rope, electric wire, etc., one end of which was tied with the ceiling fan, beams, girder, etc., inside the house in locked door or branch of a tree outside the house, and another end encircled the neck with a knot using a chair or table or tool as the base for standing, later on push them away by feet. In western countries dog chain, belt, electric cable, scarf, tie, dressing gown cord, shoe lace, etc., are used as ligature materials, which are not usually used in our country. ${ }^{15}$ The knot is usually present in the form of a simple slip knot to produce running noose or fixed by granny or reef knot, occasionally a simple loop is used. ${ }^{1}$

Suicide may be an indicator of mental instability. ${ }^{16}$ Incidence of suicidal death as a result of hanging is not unfamiliar in our society. Incidence, etiology, and nature of suicide vary from one community to another and depend mainly upon age, sex, customs, economic status, education status, and marital status, environmental and social circumstances. ${ }^{17}$ Suicide is an important manner of death in Bangladesh, represents as public health concern especially for young females. From our study findings, it can be apprehended that method of suicide by hanging is more common in Bangladesh.

\section{Conclusion}

The number of suicidal hanging cases is increasing day by day in Bangladesh. Usually young adults are the victims. A well designed and comprehensive programme is needed to identify the causative factors and prevention of suicidal hanging. To prevent suicide by hanging, status of mental health and social wellbeing should not be ignored. To improve the mental health status 
family bonding, proper education, sex education, self awareness and counseling may play important role. There should be proper employment facilities for the youth and involvement of young population in encouraging activities may reduce the rate of suicidal death by hanging in future.

\section{References}

1. Reddy KSN, Murthy OP. Mechanical Asphyxia. In: The Essentials of Forensic Medicine and Toxicology. $33^{\text {rd }}$ ed. New Delhi: Jaypee Brothers Medical Publishers (P) Ltd; 2014.p.338.

2. Nandy A. Principles of Forensic Medicine including Toxicology. $3^{\text {rd }}$ ed. New Delhi: New Central Book Agency (P) Limited; 2010.p.517-18.

3. Mohanty S, Sagu H, Mohanty MK, Patnaik M. Suicide in India: A Four Year Retrospective Study. J Forensic Leg Med. 2007;14(2):185-89.

4. Knight B, Pekka S. Knight's Forensic Pathology. $3^{\text {rd }}$ ed. London: Arnold; 2004.p.352-80.

5. Galgali RB, Sanjeeb R, Ashok MV, Appaya P, Srinivasan K. Psychiatric Diagnosis of Self Poisoning Cases: A General Hospital Study. Ind J Psych. 1998;40(3):254-59.

6. Mansur MA, Sahid MA. Trends of Hanging: An Analysis of 100 Cases. Jalalabad Med J. 2010;7(10):26-28.

7. Reddy KSN. Medicolegal Aspects of Wounds. In: The Essentials of Forensic Medicine and Toxicology. $27^{\text {th }}$ ed. Hyderabad: Mohan Printers; 2007.p.302-309.
8. Morild I. Fractures of Neck Structures in Suicidal Hanging. Med Sci Law. 1996;36(1):80-84.

9. Ahmed N, Rahman FN, Ashrafuzzaman M, Chowdhury DKP, Ali M. Overview of Organophosphorus Poisoning in Bangladesh and Medicolegal Aspects Related to Fatal Cases. JAFMC Bangladesh. 2009;5(1):41-45.

10. Gupta SC, Singh H. Psychiatric Illness in Suicidal Attempters. Ind J Psychiatry. 1981;23(1):69-74.

11. Uzun I, Buyuk Y, Gurpinar K. Suicidal Hanging: Fatalities in Istanbul Retrospective Analysis of 761 Autopsy Cases. J For Leg Med. 2007;14(7):406-407.

12. Starkuviene S, Kalediene R, Petrauskiene J. Epidemic of Suicide by Hanging in Lithuania: Does Socio Demographic Status Matter? Pub Health. 2006;120(8):769-75

13. Sharma BR, Harish D, Sharma A, Sharma S, Singh H. Injuries to Neck Structures in Deaths Due to Constriction of Neck, with a Special Reference to Hanging. J For Leg Med. 2008;15(5):298-305.

14. Eddlesto M, Rezvi SMH, Hawton K. Deliberate Self Harm in Srlanka: An Overlook Tragedy in the Developing World. BMJ. 1998;7151:133-35 .

15. Bennewith O, Gunnel D, Kapur N, Simkin S. Suicide by Hanging: Multi Centre Study Based on Coroners Records in England. BMJ. 2005; 186:260-61.

16. Phillips MR, Li X, Zhang Y. Suicide Rate in China, 1995-99. Lancet. 2002;359(9309):835-40.

17. Ahmed I, Faruque U, Afzal W, Salman M. Medicolegal Aspects of Burn Victims - a Ten Years Study. PAKJ Med Sci. 2009;25(5):797-800. 